\title{
Financial sustainability of the waste treatment projects that follow PPP contracts in Greece: a formula for the calculation of the profit rate
}

\author{
A. Sotirchos, A. C. Karmperis, K. Aravossis \& I. Tatsiopoulos \\ Sector of Industrial Management and Operational Research, \\ Department of Mechanical Engineering, \\ National Technical University of Athens, Greece
}

\begin{abstract}
This paper examines the initial budget estimation process for the implementation of waste treatment projects through Public-Private Partnership (PPPs) in Greece. The study, having as strong theoretical foundation the project's financial analysis that is included in the cost benefit analysis methodology, evaluates the financial sustainability of a waste management project. Initially, the budget estimation process that is currently used under the conventional procurement of public projects in Greece is followed and the results demonstrate that the specific process, where the investor's Profit Rate (PR) takes specific values, cannot be used in the case of a PPP. Furthermore, a new formula is developed, which calculates the minimum value of the private sector's PR, in order to determine the existence of positive cash flows during the operational phase of the project and to ensure the partnership's financial sustainability. The new formula can be a useful tool to the public decision-makers in Greece, because it helps them to evaluate the financial sustainability of the waste treatment projects that follow PPP contracts, during the conceptual phase.
\end{abstract}

Keywords: cost benefit analysis, financial analysis, financial sustainability, profit rate, Public Private Partnerships, waste treatment projects.

\section{Introduction}

Nowadays, it is common across countries that governments follow Public Private Partnership (PPP) contracts and collaborate with the private sector for the 
purpose of delivering a project or a service that is traditionally provided by the public sector. Due to the fact that PPP projects have been rapidly increased over the last decades, there are many researchers that attempt to improve the operation of PPP projects, by identifying their key aspects [1]. Especially in the waste treatment (WT) sector, there are 398 projects with private participation that are reported in the World Bank Group's database for the period 1990 to 2009 [2], while the investments are estimated in US\$ 15,878 million. Furthermore, other authors refer to the implementation of large WT projects in different countries, such as China, India, Indonesia, Thailand, Vietnam, Turkey, Mexico, Malaysia and Australia [3-5]. These projects are mainly implemented by following the Build-Operate-Transfer (BOT) type, which is the most used contract type in PPPs [6]. However, a common point between different PPP contract types is that the PPPs are long-term agreements for the provision of high quality infrastructure, products or services [7], while there are significant technical, legal and economic risks that are shared between the public and private sectors [8].

In Greece, these contract types are presented in various forms, many decades ago [9] and are mainly implemented recently, under the specialized form of concessions for the construction of 3 major projects of significant and national importance; the Rio - Antirio Bridge, the Attiki Odos Highway and the International Airport of Athens [10]. For these projects, the approval by the public authorities was a cumbersome process since the legal framework in Greece was highly segmented. Currently, the specific legal and institutional framework for PPPs in Greece is established in 2005 under the Law 3389. According to this Law, two institutions are developed, the special secretariat for PPP and the inter-ministerial committee, which execute the initial assessment process for a proposed PPP project. In 2006, the manual for the implementation of projects and services through PPP is issued by the special secretariat [11], while the "Green Paper on PPPs" (EU Committee, 2006), containing 22 questions relevant to the issues of partnership contracts is sent by the European Commission to Member States [12]. Specifically, between the 52 PPP projects that are already approved by the Greek inter-ministerial committee, there are two environmental projects for the implementation of WT units in the region of Western Macedonia and the municipality of Rafina respectively. However, due to the fact that in Greece the PPP market opened quite recently, while the PPP [13] and the WT projects [14, 15] require complicated procedures, it is concluded that the WT projects that are considered to be implemented through PPPs in Greece, include a high degree of complexity [16]. Thus, a tool that can be used by the decision-makers during the feasibility stage of a WT PPP project, in order to ensure the partnership's financial sustainability, will be very useful.

\section{Public procurement framework in Greece}

According to the European Community and the national law, during all phases of public projects, there have to be in act the principles of equal treatment, isonomy, transparency, proportionality, public interest protection, private rights protection, free competition and environmental protection. Public procurement 
rules mean that the procedure should follow one out of three routes, which are the open procedure, the restricted procedure and the negotiated one [17]. The open procedure is distinguished due to the promotion of transparency and in most cases the international competitive bidding process is followed [18], where the contracting authorities are obliged to use as a key criterion for the award, either the lowest price or the most economically advantageous tender. However, due to the fact that the lowest price criterion itself does not ensure the value for money of the PPP projects, as it does not take into account the project's technical and quality parameters, several key factors for the PPP procurement process are suggested by the literature. Indicatively, Araujo [19] and Zhang [20, 21] suggest some specific criteria for the concessionaire selection, while Zhang [22] identifies 21 specific best value contributing factors, in order to choose the right private sector partner. On the other hand, many researchers highlight crucial issues that arise in the public procurement for environmental projects [23] and especially for WT projects $[24,25]$. Generally, several existing models can be used either in the tender evaluation $[26,27]$ or in the negotiation process of the PPP projects [28]. However, the application of these models in the procurement process for a WT PPP project requires the estimation of the project's budget by the public sector, during the feasibility stage of the project. Furthermore, the operational phase of the PPP contracts is too long, 20 to 30 years [29], so it is very difficult to model the initial budget estimation process. Main objective of this paper is to develop a formula which can be used for the calculation of the Profit Rate's (PR) minimum value on behalf of the Special Purpose Vehicle (SPV), so as to ensure the project's financial sustainability.

\section{Evaluation of the waste treatment PPP projects}

Generally, a WT project's evaluation process is implemented through the Cost Benefit Analysis (CBA), the life cycle assessment or the multi-criteria analysis [30]. However, the CBA is distinguished, as it can be used for the evaluation of alternative types of WT projects [31,32]. The calculation formula for the WT projects that are implemented through PPP contracts in Greece, which is developed here, has as theoretical foundation the CBA guide for investment projects, issued by the European Commission (EC) [33]. A remarkable point is that the submission of a project proposal which includes a CBA is mandatory for all large projects that are co-financed by the European Community for the 20072013 period, where large are considered the environmental projects whose budget are over 25 million euros. According to the EC's guide, the financial analysis is a basic step in the CBA. The main purpose of the financial analysis for a PPP project is the use of the project cash flow forecasts, in order to calculate the net return indicators for the SPV, through the annual payments by the public sector. Further, the financial analysis includes the evaluation of the project's financial sustainability, which is crucial in all types of investments. 


\subsection{Financial indicators}

The financial indicators which are calculated in the financial analysis, is the Net Present Value (NPV) and the Internal Rate of Return [34]. Specifically in PPP projects, the performance of the private capital is implemented through the calculation of the financial NPV of the private capital NPV (Kp). Furthermore, the investment's profitability is demonstrated by the Profitability Index (PI), which is calculated by the inflows in present value (PV), divided by the outflows in PV respectively. In PPP projects, the SPV's PI takes into account all the net inflows divided by the outflows, which are the initial capital for the infrastructure development plus the capital that will be invested annually, e.g. the payment of the subcontracting agreements, or the loan repayments, etc.

\subsection{Financial sustainability}

Additionally, some key points that are included in the financial analysis of the PPP projects is the bank loan's interest rate as well as the interest rate, i.e. the inflation, that is used for the adjustment of the cash flows in future value (FV), because both have an impact on the annual net cash flows, which are calculated through the annual inflows minus the outflows of the SPV. We mention that a project is classified as financial sustainable, when it does not incur the risk of running out of cash in the future. Therefore, the financial sustainability's criterion is the annual cash flows to be positive for the SPV during the project's operational phase.

\section{Case study: financial analysis of a waste treatment project that follows a BOT contract in Greece}

In order to achieve the desired development of a formula for the calculation of the PR, an illustrative case of a BOT project in Greece is considered and specifically is evaluated in the financial sustainability's criterion. The project is an investment in the field of WT, for the reuse of well purified waste water for multiple purposes after an intensive tertiary treatment process. It takes place in Greece and includes the construction of wastewater treatment facilities for a city of 200,000 residents.

\subsection{Assumptions}

The cash flows arising in different years are calculated by the discount rate following the discount cash flow analysis (DCFA) [36], while only the financial inflows and outflows are considered, i.e. the value added tax, the depreciation of fixed assets and other accounting tools are not counted for the sake of simplicity. The time horizon that is selected to run the analysis consists of a 20 year operational phase, plus 1 year as the implementation phase for the infrastructure's construction. 


\subsubsection{Initial investment, expenditures and revenues}

The initial investment cost for the construction of the WT facilities, is estimated at $€ 48,000,000$, which does not include general costs or profits. This was originally divided into equal flows and distributed annually in the project's operational phase, i.e. $€ 2,400,000$ per year in $\mathrm{PV}$, while this cost is funded by a bank agency through loan. The annual operational cost for the 1 st year of the operational phase is estimated in $€ 3,600,000$ in $\mathrm{PV}$, where also there are no general costs or profits. These costs met by the private contractor as investments outflows, while inflows are the annual payments from the public sector. Furthermore, the maintenance cost for the 1 st year is estimated in $0.4 \%$ of the construction budget, i.e. $€ 220,000$ in PV. Other assumptions that are used in the financial analysis, is the $6.65 \%$, as the interest rate of the loan for the SPV, while the annual repayments are also fixed and the loan's amortization period is equal to the operational phase, i.e. 20 years.

\subsubsection{Discount rate}

Additionally, the discount rate that is suggested by the EC for the investments implemented in the Euro-zone during the programming period 2007-2013 is 5\% for a long term. Notwithstanding the above rate may vary, depending on the type of investment, e.g. in PPP projects [33]. This case study uses the $7.5 \%$ as the discount rate, which is normal to cases of PPP projects in the Greek market.

\subsection{Financial indicators}

All data are adjusted in FV following the inflation, which is considered 3.0\%. In the financial analysis, the process flowchart for the calculation of the NPV is illustrated in the following Figure 1. The NPV and the PI evaluation indicators are calculated on behalf of the SPV, who is the contractor and operator of the investment. Specifically, in the case that the NPV takes a negative value and/or the $\mathrm{PI}<1$, then the SPV should reject the project, otherwise he should select it. In these calculations, the total capital managed by the involved participants is taken into account, i.e. the SPV, the public sector and the bank loan.

\subsection{Consideration of financial scenarios for different values of the PR}

In order to select the best proposal for the estimation of the annual payments by the public sector, there are two scenarios tested, where the initially estimated costs are increased by $18 \%$ or $28 \%$ respectively, according to the PR designated by the legislation of public construction projects in Greece.

Generally, the project's budget estimation process specifies that these rates are used in the increasing of the costs that arise by the uniform tariffs work of the government's public works department, which contain relevant articles, prices of materials and works. Indicatively, the analytical costs of construction, electromechanical and other works are calculated and these costs are increased by $18 \%$ for projects financed by the public investment budget and by $28 \%$ in other cases (National Law, 1985; 2008), where these rates correspond to general costs and profit. A last step is to increase the rate of unplanned work of the 


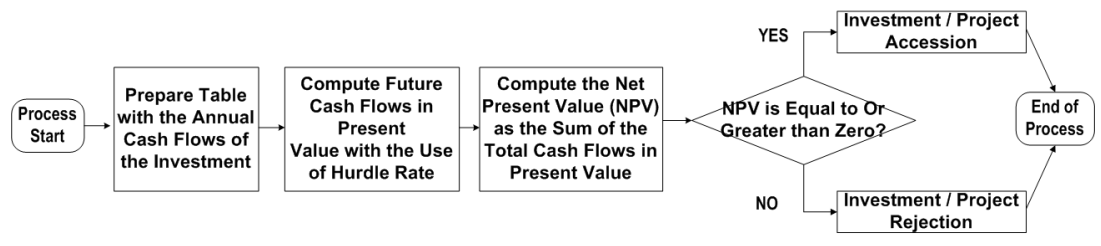

Figure 1: $\quad$ Process flowchart for the estimation of the Net Present Value.

project and the percentage of the value added tax. In the present case study, the resulting calculations of the NPV and the PI for both the scenarios of $18 \%$ and $28 \%$ respectively, are presented in Table 1 . Additionally, the results arising through the evaluation of these scenarios in the financial sustainability criterion are also included in Table 1, while the diagrams depicting the cash flows in FV are illustrated in Figures 2 and 3 respectively. We mention that the PI and the PR take different values, because the cash flows that are adjusted with the PR are in $\mathrm{FV}$ and the relative cash flows for the calculation of the PI are discounted in PV.

Table 1: $\quad$ Project's financial sustainability.

\begin{tabular}{cccccc}
\hline & & & \multicolumn{3}{c}{ Financial Sustainability } \\
\cline { 4 - 6 } Profit Rate: & Profitability & Net Present & Lack of & Switching & Availability \\
& Index & Value & Liquidity & Point & Capital \\
\hline $18.00 \%$ & 1.01417 & $1,350,000$ & $0-7$ years & $8^{\text {th }}$ year & $8-20$ years \\
$28.00 \%$ & 1.10012 & $9,530,000$ & $0-2$ years & $3^{\text {rd }}$ year & $3-20$ years \\
$30.20 \%$ & 1.11903 & $11,330,000$ & - & - & $0-20$ years \\
\hline
\end{tabular}

The evaluation of the diagrams in Figures 2 and 3 focuses on the existence of the switching point, where total inflows are equal to outflows and there is a change in the project's financial liquidity. In the present case, the first scenario where the estimated costs are increased with the PR of $18 \%$, there is availability of capital from the 8th year until the end of the project life, but there are negative cash flows for the private sector by entering the operational phase, which last for 7 years, when there is a switching point. Furthermore, the second scenario, where the estimated costs are increased with the PR of $28 \%$, there is also a lack of liquidity by entering the operational phase for 2 years, when there is a switching point. According to these results, both the scenarios are evaluated us financial unsustainable. Conclusively, the WT projects that follow PPP contracts in Greece, where the repayment of the bank loan is at a fixed rate with fixed payments, it is inefficient to follow the same process with the conventional public project procurement process, in order to estimate the project's budget, i.e. to increase the estimated costs with a PR of $18 \%$ or $28 \%$ respectively. The above results suggest the necessity to develop a formula for the calculation of the minimum price of the PR, so as to exclude the negative cash flows during the project's operational phase and to ensure the project's financial sustainability. 


\section{Development of a formula for the calculation of the PR}

In order to develop a formula for the calculation of the minimum price of the PR in a WT PPP project, where the bank loan is repaid with equal payments throughout the project's operational phase, the following mathematical demonstration is used. The annual flows for the SPV are calculated through the next formula:

$$
\mathrm{f}(\text { annual })(\mathrm{t})=\mathrm{FV}(\text { inflows })(\mathrm{t})-\mathrm{FV}(\text { outflows })(\mathrm{t})
$$

where $(t)=(1,2,3,4, \ldots, 20]$.

\subsection{Total outflows}

Let $a$ denote the initial capital that is funded through the loan, $p$ the interest rate and $n$ the amortization period in years. Therefore, the FV of outflows for the loan repayment varies according to the following function, $h(t)$. Following the method of progressive amortization, the annual payments of a loan with a fixed interest, are calculated by the formula:

$$
h(t)=(\text { interest }+ \text { amortization })=\frac{a}{\sum_{1}^{n} \frac{1}{(1+p)^{n}}}
$$

Let $c$ denote the operational costs for the 1st year of the operational phase, which is increased with a rate $r$ per year, so the FV of this cost $g(t)$ is calculated with the formula:

$$
g(t)=c \times(1+r)^{t}
$$

\subsection{Total inflows}

Let $R(t)$ denote the FV of the SPV's inflows, which arise through the annual payments by the public sector. These payments are increased following the interest rate $r$, as shown in formula:

$$
R(t)=(1 \text { st paymen }) \times(1+r)^{\mathrm{t}}
$$

Payment of the 1st year is estimated through the initial invested capital $a$, which is divided equally to the years of the operational phase $v$, plus the annual operating costs, multiplied by the (1+PR):

$$
\begin{gathered}
(1 \text { st payment })=\left(\frac{a}{v}+c\right) \times(1+P R) \stackrel{(4)}{\Rightarrow} \\
R(t)=\left(\frac{a}{v}+c\right) \times(1+P R) \times(1+r)^{\mathrm{t}}, \mathrm{t}=(0,1,2, \ldots, 20]
\end{gathered}
$$


Formulae (1), (2), (3) and (5) give:

$$
\begin{gathered}
(1) \stackrel{(2),(3),(5)}{\Leftrightarrow} \mathrm{f}_{(\text {annual })}(\mathrm{t})=R(t)-g(t)-h(t) \Rightarrow \\
\mathrm{f}(\mathrm{t})=\left(\frac{a}{v}+c\right) \times(1+P R) \times(1+r)^{\mathrm{t}}-c \times(1+r)^{\mathrm{t}}-\frac{a}{\sum_{1}^{n}(1+p)^{n}}
\end{gathered}
$$

As shown by Formula (6), in the case that the loan's amortization period is equal to the operational phase, then $n=t$. According to the financial sustainability criterion, annual cash flows for the SPV should be positive. Further, there is: $\mathrm{f}(1)<\mathrm{f}(2)<\ldots<\mathrm{f}(\mathrm{n})$. Thus, Formula (6), for the $\mathrm{f}(1)>0$, results in:

$$
\begin{gathered}
f(1)=\left(\frac{a}{v}+c\right) \times(1+P R) \times(1+r)-c \times(1+r)-\frac{a}{\sum^{n} \frac{1}{1(1+p)^{n}}}>0 \Rightarrow \\
c \times(1+r)+\frac{a}{\sum^{n} \frac{1}{1}(1+p)^{n}}-1 \\
P R>\frac{\left(\frac{a}{v}+c\right) \times(1+r)}{}
\end{gathered}
$$

where: $\mathrm{a}=$ capital funded through loan, $\mathrm{v}=$ operational phase (in years), $\mathrm{c}=$ annual operating costs, $r=$ interest rate (inflation), $p=$ loan's interest rate (fixed) and $\mathrm{n}=$ loan's amortization period (in years).

The above Formula (7) gives the desired result, as it calculates the minimum value of the PR, so as to exclude negative cash flows during the operational phase of the project. In the specific case study, the result that is calculated by the formula is $\mathrm{PR}=30.20 \%$, as presented in Table 1 . Furthermore, the sensitivity of the minimum PR value in the above variables is estimated with the use of this formula. Indicatively, the results of the sensitivity analysis are illustrated in Figure 4, where is presented the minimum value that the PR has to take, according to a change of the variables' values in a range of $(-15 \%,+15 \%)$, in order to achieve positive cash flows throughout the operational phase of the project for the SPV and to ensure the project's financial sustainability.

\section{Conclusions}

This research, having as a strong theoretical foundation the financial analysis approach, as it is described in the EC's guide to CBA for investment projects, examines the budget estimation process that is used under the conventional public procurement framework for a WT project that follows a PPP contract in 


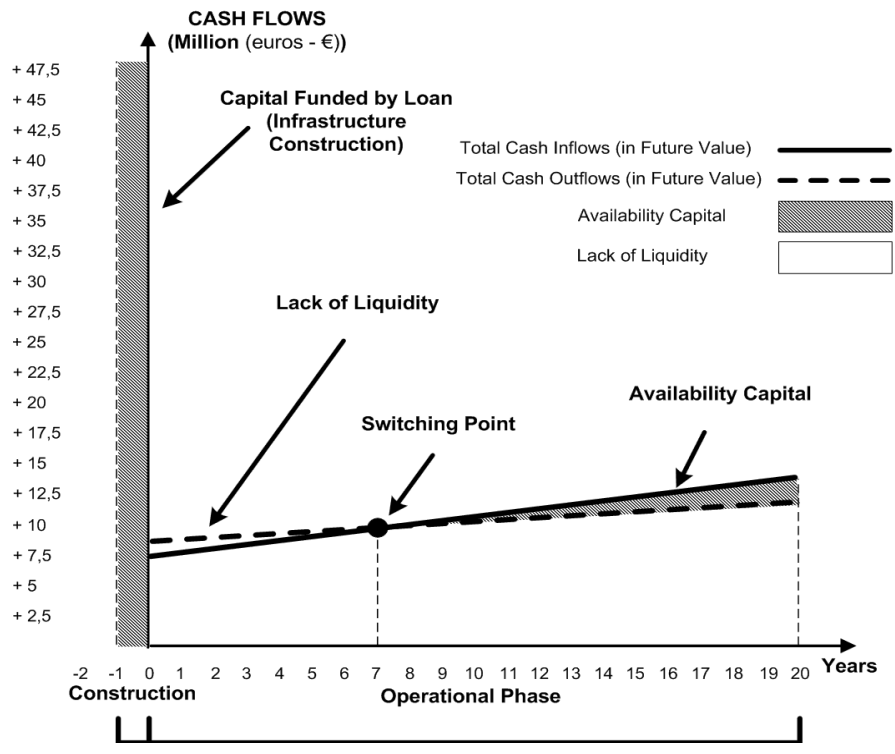

Figure 2: $\quad$ Cash flow diagram with payments adjustments at the $\mathrm{PR}=18 \%$.

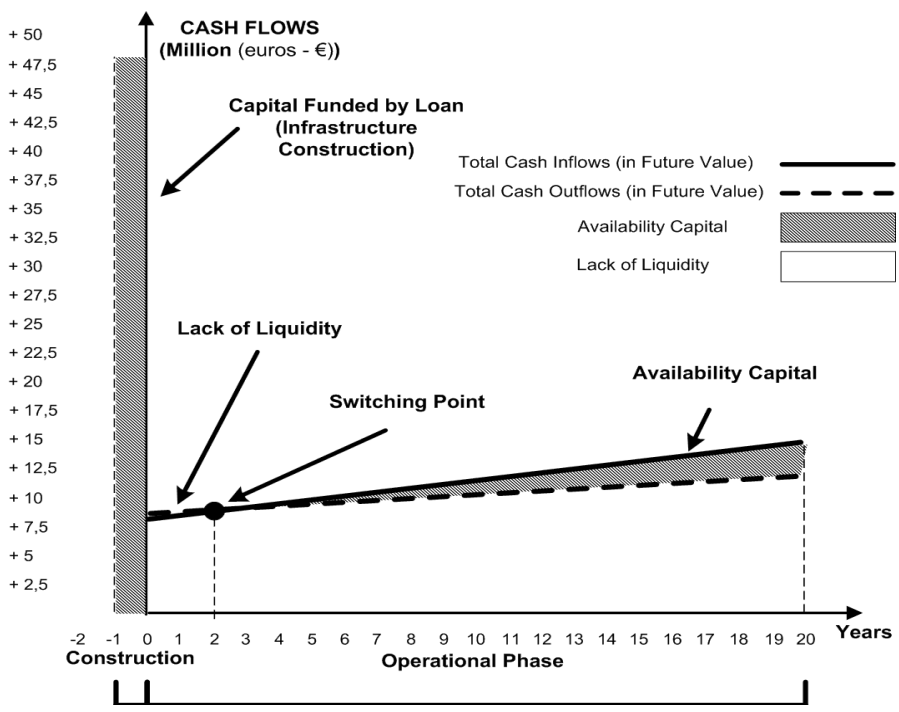

Figure 3: Cash flow diagram with payments adjustments at the $\mathrm{PR}=28 \%$. 


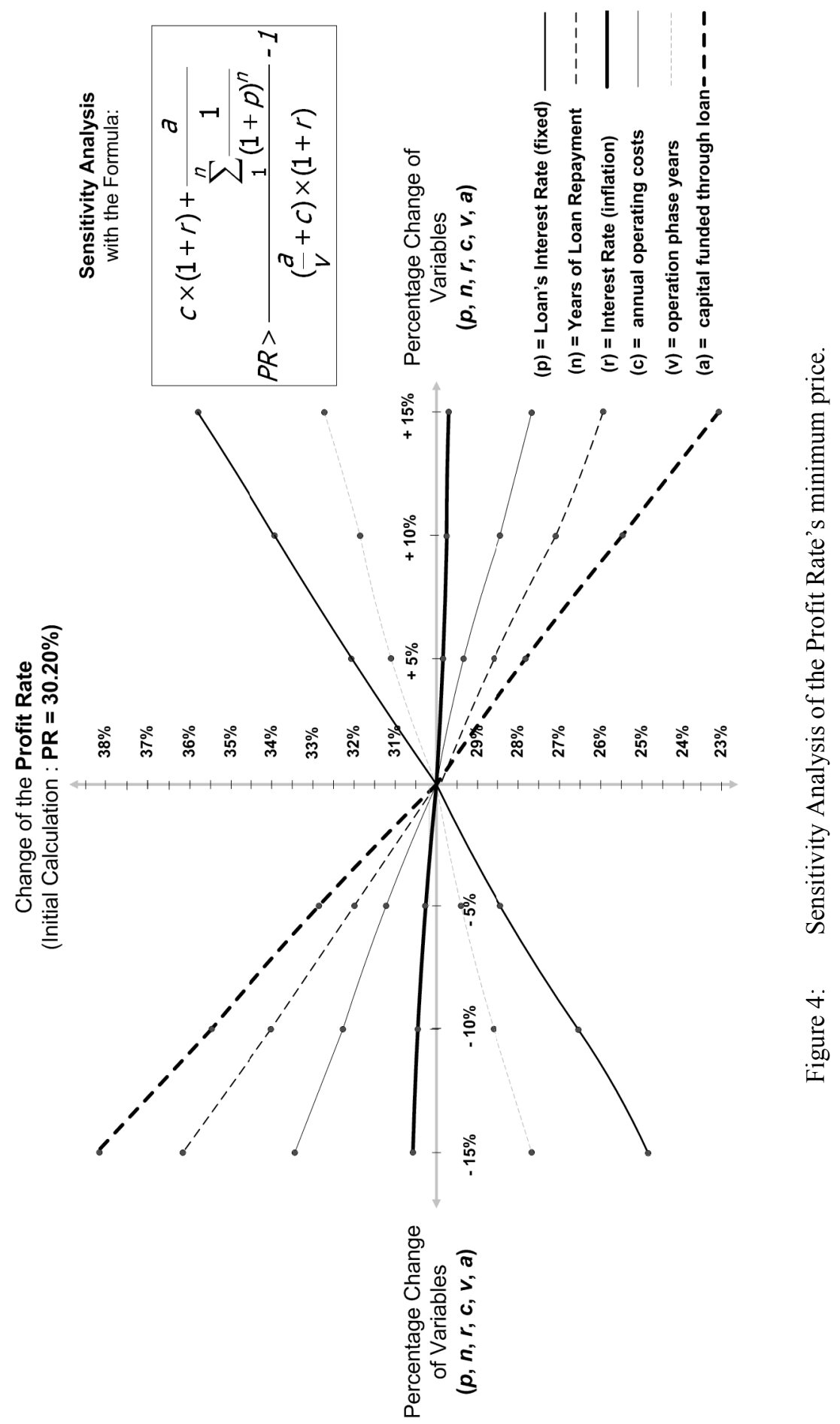


Greece. Specifically, the financial analysis of a BOT project is presented and two scenarios for the annual payments are evaluated, with a PR of $18 \%$ and $28 \%$ respectively. The results demonstrate that the specific PRs cannot be used for the PPP projects in Greece. Furthermore, taking into consideration the financial sustainability criterion, a new mathematic formula is developed. With the use of the specific formula in the case study, it is demonstrated that avoiding of liquidity shortage and thus the increasing of the financial sustainability in a 20 year time horizon, is achieved with the annual payments adjusted to a minimum PR value of $30.2 \%$. Moreover, this formula is used in the implementation of the sensitivity analysis for the PR's minimum value with the six variables which act upon it. This formula can be a useful tool, not only for the public sector during the conceptual phase of a WT PPP project, but for all stakeholders, while it can be further used in other type of investment projects, during the initial stage.

\section{References}

[1] Tang L., Shen Q., Cheng E. W.L., A review of studies on Public-Private Partnership projects in the construction industry, International Journal of Project Management, doi:10.1016/j.ijproman.2009.11.009.

[2] Pongsiri, N., Regulation and public private partnerships, International Journal of Public Sector Management, 15(6), pp. 487-495, 2002.

[3] Grimsey, D. \& Lewis, M.K., Public Private Partnerships, the Worldwide Revolution in Infrastructure Provision and Project Finance (Chapter 1). The nature of partnerships, Edward Elgar: Cheltenham, pp.5-9, 2007.

[4] Yescombe, E.R., Public-Private Partnerships: Principles of Policy and Finance (Chapter 2). PPPs-For and Against, Published by Elsevier Ltd: Oxford, pp.15-28, 2007

[5] Haarmayer, D. \& Mody, A., Financing Water and Sanitation Projects - The Unique Risks, The World Bank Group, Finance, Private Sector and Infrastructure Network, 151, pp. 1-4, 1998.

[6] Zhang, X-q. \& Kumaraswamy, M.M., Hong Kong experience in managing BOT projects, Journal of Construction Engineering and Management, 127(2), pp. 154-162, 2001.

[7] Karmperis, A.C., Sotirchos, A., Aravossis, K. \& Tatsiopoulos, I., Funding evaluation model for the implementation of wastewater treatment projects through Public Private Partnerships. Environmental Economics and Investment Assessment III, vol. 131, eds. K. Aravossis \& C.A. Brebbia, WIT Press: Southampton, pp. 147-160, 2010.

[8] $\mathrm{Ng}, \mathrm{A}$. \& Loosemore, M., Risk allocation in the private provision of public infrastructure, International Journal of Project Management, 25(1), pp. 66$76,2006$.

[9] Verveniotis, P.C., Implementation of Projects with the Exploitation Concession-BOT Contracts: Construction and Arbitration, Sakkoulas: Athens and Komotini, pp. 78-79, 1993 (in Greek). 
[10] Roumboutsos, A. \& Anagnostopoulos, K.P., Public-private partnership projects in Greece: risk ranking and preferred risk allocation, Construction Management \& Economics, 26(7), pp. 751-763, 2008.

[11] Ministry of Finance, Guide for the Implementation of PPP in Greece, Athens, 2006, http:/www.sdit.mnec.gr/en/infopoint/implementation/

[12] European Union Committee, Green Bible for Public Private Partnerships, Brussels, 2004.

[13] Alonso-Conde, A.B., Brown, C. \& Rojo-Suarez, J., Public Private Partnerships: Incentives, risk transfer and real options. Review of Financial Economics, 16(4), pp. 335-349, 2007.

[14] Linke, P. \& Kokossis, A., Advanced process systems design technology for pollution prevention and waste treatment, Advances in Environmental Research, 8(2), pp. 229-245, 2004.

[15] Seadon, J.K., Integrated waste management-Looking beyond the solid waste horizon, Waste Management, 26(12), pp. 1327-1336, 2006.

[16] Martimort, D. \& Pouyet, J., To build or not to build: Normative and positive theories of public-private partnerships, International Journal of Industrial Organization, 26(2), pp. 393-411, 2008.

[17] European Union, Co-ordination in the contracting process for Public Projects: Procurements and Services, Directive 18, 2004.

[18] Asian Development Bank, Procurement Guidelines, Ch. II, pp. 18-19, 2001.

[19] Araujo, AR., Procurement in Privately Provided Infrastructure Projects Financed by the World Bank, World Bank, pp. 16-17, 1998.

[20] Zhang, X., Concessionaire Selection: Methods and Criteria, Journal of Construction Engineering and Management, 130(2), pp. 235-244, 2004.

[21] Zhang, X., Criteria for Selecting the Private-Sector Partner in PublicPrivate Partnerships, Journal of Construction Engineering and Management, 131(6), pp. 631-644, 2005.

[22] Zhang, X., Public Clients' Best Value Perspectives of Public Private Partnerships in Infrastructure Development, Journal of Construction Engineering and Management, 132(2), pp. 107-114, 2006.

[23] Geng, Y. \& Doberstein, B., Greening government procurement in developing countries: Building capacity in China, Journal of Environmental Management, 88(4), pp. 932-938, 2008.

[24] Lozier, J.C., Smith, G., Chapman, J.W.\& Gattis, D.E., Selection, design, and procurement of a demineralization system for a surface water treatment plant, Desalination, 88(1-3), pp. 3-31, 1992.

[25] Francis Rillaerts, F., Concessions in the water sector, Desalination, 124(13), pp. 13-17, 1999.

[26] Hatush, Z. \& Skitmore, M., Contractor selection using multi-criteria utility: an additive model, Building and Environment, 33(2-3), pp. 105-115, 1998.

[27] Pongpeng, J. \& Liston, J., TenSeM: a multi-criteria and multi-decisionmakers' in tender evaluation, Construction Management and Economics, 21(1), pp. 21-30, 2003. 
[28] Liou, F-M. \& Huang, C-P, Automated Approach to Negotiations of BOT Contracts with the Consideration of Project Risk, Journal of Construction Engineering and Management, 134(1), pp. 18-24, 2008.

[29] Grimsey, D. \& Lewis, M.K., Are Public Private Partnerships value for money? Evaluating alternative approaches and comparing academic and practitioner views, Accounting Forum, 29(4), pp. 345-378, 2005.

[30] Çelik, B., Girgin, S., Yazıcı, A., Ünlü, K., A decision support system for assessing landfill performance, Waste Management, 30(1), pp. 72-81, 2010.

[31] Morrissey, A.J., Browne, J, Waste management models and their application to sustainable waste management, Waste Management, 24(3), pp. 297-308, 2004.

[32] Lavee, D., A cost-benefit analysis of a deposit-refund program for beverage containers in Israel, Waste Management, 30(2), pp. 338-345, 2010.

[33] European Commission, Guide to Cost - Benefit Analysis of Investment Projects, Directorate General Regional Policy, Brussels, 2008.

[34] Chiang, Y.H., Cheng, E.W.L. \& Lam, P.T.I., Employing the NPVConsistent IRR Methods for PFI Contracts, Journal of Construction Engineering and Management, 136(7), pp. 811-814, 2010. 